\title{
Preparation of $\mathrm{CO}_{2} / \mathrm{N}_{2}$ cryogenic slurry and its pipeline flow characteristics
}

\author{
ZHANG Xin-hai ${ }^{1,2^{*}}$, DOU Kai ${ }^{1,2}$, ZHANG Guo-wei ${ }^{1,2}$, LI Xun-guang ${ }^{1,2}$, CHENG Wang-shou ${ }^{1,2}$, ZHU Hui ${ }^{1,2}$ \\ ${ }^{1}$ School of Safety Engineering, Xi'an University of Science and Technology, Xi'an, Shaanxi Province, 710054 China;
}

\begin{abstract}
It was proposed to use $\mathrm{CO}_{2} / \mathrm{N}_{2}$ to effectively prevent and control Class A solid spontaneous fires such as coal. The preparation process of $\mathrm{CO}_{2} / \mathrm{N}_{2}$ cryogenic slurry pipeline and its pipeline flow characteristics were studied. The temperature field, pressure field and phase change characteristic changed during the transportation of the $\mathrm{CO}_{2} / \mathrm{N}_{2}$ mixture in the pipeline are analyzed by numerical simulation. The results showed that: the fluid in the pipeline exchanged heat and started to contact at a position of $0.1 \mathrm{~m}$ in the pipeline. The temperature first rapidly dropped to the lowest temperature of $103 \mathrm{~K}$, and then the fluids in the range of $0.1 \mathrm{~m}$ to $0.3 \mathrm{~m}$ were fully mixed, and the temperature rised to $164 \mathrm{~K}$. The temperature was consistent with the equilibrium state in the pipe, and the temperature was gentle and stable; the pressure in the pipe was on the whole downward trend, and each position along the main pipe produced a positive pressure difference relative to the end of the pipe. The closer to the mixing place, the greater the corresponding pressure difference; During the mixing process, $\mathrm{LN}_{2}$ was acted as a cold source to sublime $\mathrm{CO}_{2}$ to form dry ice particles. And through the cryogenic fluid mixing experiment, the temperature distribution in the pipeline, range of the dry ice particle generation position, and the dry ice particle generation phenomenon was measured. The results showed that the mixing was completed within $0.8 \mathrm{~m}$ of the pipeline, and the temperature in the tube rised to $168 \mathrm{~K}$ and remain stable. The data were basically consistent. And dry ice particles generated at the temperature of $194.5 \mathrm{~K}$, and a diffuse gas cloud formed at the outlet with the momentum of the jet.
\end{abstract}

\section{Introduction}

China is rich in coal resources, but due to the influence of coal seam geological conditions, mining technology, ventilation management and coal's own characteristics, the annual direct burning loss due to spontaneous combustion reaches $10 \sim 13.6 \mathrm{Mt}[1-2]$. Coal spontaneous combustion disasters have caused serious waste of resources and even casualties. Its governance has always been a hot issue of research [3-5].

Countries around the world have done a lot of work in the treatment of underground coal fires, and successively proposed technologies such as yellow mud grouting, coal seam water injection, pressure equalization, inhibitors, high-expansion foam, and inert gas injection in the goaf [6-8]. Among them, the inert gas anti-extinguishing cooling rate is slow, and the cooling effect is relatively poor. Based on this, in order to make up for the shortcomings of traditional fire-fighting technology, many experts and scholars have done a lot of research work on $\mathrm{CO}_{2}$ fire-fighting and its application technology, which has good cooling performance, oxygen reduction, strong inertia, and convenient transportation. Gao Yukun and others used Fluent to simulate the dry ice in the goaf to release low-temperature $\mathrm{CO}_{2}$ to prevent fire and extinguishing technology, and found that low-temperature $\mathrm{CO}_{2}$ quickly spreads over the goaf, which has a good firefighting effect [9]. Ann G. Kim et al. used a cryogenic slurry made by mixing liquid nitrogen and liquid $\mathrm{CO}_{2}$ on site to extinguish the fire on the abandoned coal gangue hills in Ohio, and achieved good results [10]. Chaiken invented a patent for low-temperature slurry of liquid nitrogen and granular $\mathrm{CO}_{2}$ used to extinguish mine fires [11]. Zhang Xinhai and others invented a method and device for preventing and extinguishing snow from cryogenic inert gas. The solid carbon dioxide particles formed by sublimation are dispersed in liquid nitrogen to form a slurry that is easy to transport, covering the surface and cracks of spontaneous combustion coal. Quickly cool down and isolate oxygen to achieve efficient fire fighting $[12,13]$. The dry ice particles in the cryogenic slurry are formed by the condensation of low-temperature carbon dioxide gas. Yoshiyuki uses a vertical dry ice crystallizer made of Pyrex to visually observe the $\mathrm{CO}_{2}$ sublimation process. Under the action of low temperature, $\mathrm{CO}_{2}$ directly undergoes sublimation to produce dry ice particles [14]. Li Juan et al. introduced $\mathrm{CO}_{2}$ into saturated liquid nitrogen through different types of pipelines to form fine and dispersed dry ice particles and a uniform solid-liquid mixture in the pipeline. They studied the particle size and pipe blockage during the mixing process and found that capillary tubes were used. Tube blockage does not occur sometimes [15]. Yuan Lingcheng studied the $\mathrm{CO}_{2}$ sublimation mechanism in the $\mathrm{N}_{2} / \mathrm{CO}_{2}$ binary mixture system, and analyzed the $\mathrm{CO}_{2}$ sublimation under different flow characteristics and cooling conditions [16, 17]. Jiang

Corresponding author's e-mail: Zhangxinh71@126.com 
Xiaobo studied the $\mathrm{CO}_{2}$ sublimation process and the crystal crystallization during the sublimation process, and obtained crystal pictures through optical instruments, and summarized the nucleation probability and the size of the nucleation [18]. Liu Yao analyzed the influencing factors of $\mathrm{CO}_{2}$ sublimation heat transfer under different boundary conditions and found that the lower the $\mathrm{N}_{2}$ temperature at the inlet, the higher the $\mathrm{CO}_{2}$ sublimation temperature [19, 20]. Fan Yafang used numerical simulation to study the sublimation heat transfer process of $\mathrm{UF}_{6}$ gas in an $8 \mathrm{~L}$ condensing vessel [21]. Wang Yaning proposed a onedimensional dynamic model for simulating the sublimation process of $\mathrm{CO}_{2}$ in a low-temperature surface mixed gas, and revealed the change law of parameters such as temperature distribution and sublimation time during the sublimation process [22].

In summary, the current $\mathrm{CO}_{2}$ sublimation prevention and control of coal spontaneous combustion at room temperature mainly focuses on the microscopic mechanism of the sublimation process, such as the formation and growth of $\mathrm{CO}_{2}$ solid crystal nuclei. There are few researches in the field of coal mine fire prevention and extinguishing. Research on the formation and flow characteristics of inert gas slurry in pipelines lays a theoretical foundation for fire-fighting technology. In this paper, $\mathrm{CO}_{2}$ gas is converted into small solid particles by low-temperature liquid nitrogen $\left(\mathrm{LN}_{2}\right)$ and dispersed in $\mathrm{LN}_{2}$ to form inert gas slurry. Fluent numerical simulation and experimental verification are used to study the temperature, pressure and phase of $\mathrm{N}_{2}$ and $\mathrm{CO}_{2}$ in the pipeline during the mixed transportation. The characteristics of state change provide relevant basis and reference for the cryogenic slurry anti-extinguishing technology to realize the solid-liquid two-phase transport into the coal spontaneous combustion high temperature area, so that the $\mathrm{CO}_{2}$ is attached to the surface of the spontaneous combustion coal body in the form of small solid particles and cracks to cool down Oxygen barrier.

\section{Numerical simulation}

\subsection{Geometric model and mesh}

The gas mixing pipeline used in the simulation in this paper adopts a three-way pipe with a diameter of $20 \mathrm{~mm}$ and a length of $1200 \mathrm{~mm}$. The geometric model is shown in Figure 1: $\mathrm{CO} 2$ enters from inlet 1 of the pipeline, and LN2 enters from inlet 2. Figure 2 shows the results of meshing the pipeline using the Mesh module. After mesh inspection, the geometric model mesh quality is greater than 0.4 , accounting for 99.24 , which meets the solution requirements.

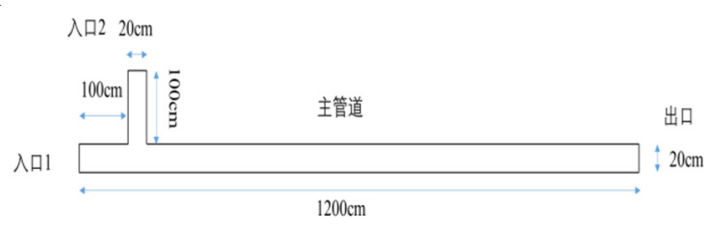

Fig.1 Schematic diagram of the pipeline model

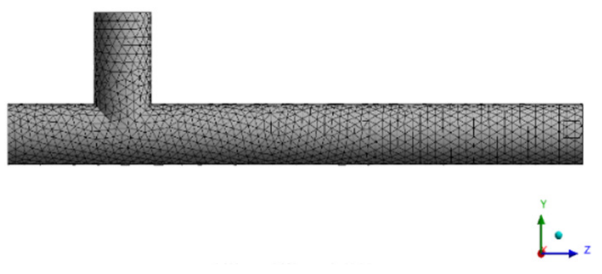

Fig.2 Mesh of the geometric model

\subsection{Mathematical model}

The simulation of incompressible viscous fluid uses the standard k- $\varepsilon$ model to calculate the flow state in the pipeline [23]. In the process of fluid pipeline flow, the law of conservation of mass, the law of conservation of momentum and the equation of conservation of energy are observed. The specific differential equation is as follows:

Continuity equation:

$$
\frac{\partial \rho}{\partial t}+\frac{\partial \rho u}{\partial x}+\frac{\partial \rho v}{\partial y}+\frac{\partial \rho w}{\partial z}=0
$$

The steady-state momentum equation:

$$
\begin{aligned}
& \frac{\partial\left(\rho u_{i} u_{j}\right)}{\partial \mathrm{x}_{\mathrm{i}}}=-\frac{\partial \rho}{\partial \mathrm{x}_{\mathrm{i}}}+\rho \mathrm{g}_{\mathrm{i}}+\frac{\partial}{\partial \mathrm{x}_{\mathrm{j}}} \\
& {\left[\mu\left(\frac{\partial u i}{\partial u j}+\frac{\partial u j}{\partial \mathrm{x}_{\mathrm{i}}}\right)-\overline{\rho u_{i}^{\prime} u_{j}^{\prime}}\right]}
\end{aligned}
$$

Energy conservation equation:

$$
\frac{\partial(\rho T)}{\partial t}+\operatorname{div}(\rho u T)=\operatorname{div}\left(\frac{K}{c_{p}} \operatorname{grad} T\right)+S_{T}
$$

Mass transfer differential equation:

$$
\begin{gathered}
\frac{\partial \rho_{\mathrm{A}}}{\partial t}+u_{x} \frac{\partial \rho_{\mathrm{A}}}{\partial x}+u_{y} \frac{\partial \rho_{\mathrm{A}}}{\partial y}+u_{z} \frac{\partial \rho_{\mathrm{A}}}{\partial z}= \\
D_{\mathrm{AB}}\left(\frac{\partial^{2} \rho_{\mathrm{A}}}{\partial x^{2}}+\frac{\partial^{2} \rho_{\mathrm{A}}}{\partial y^{2}}+\frac{\partial^{2} \rho_{\mathrm{A}}}{\partial z^{2}}\right) \\
\frac{\partial \rho_{\mathrm{B}}}{\partial t}+u_{x} \frac{\partial \rho_{\mathrm{B}}}{\partial x}+u_{y} \frac{\partial \rho_{\mathrm{B}}}{\partial y}+u_{z} \frac{\partial \rho_{\mathrm{B}}}{\partial z}= \\
D_{\mathrm{AB}}\left(\frac{\partial^{2} \rho_{\mathrm{B}}}{\partial x^{2}}+\frac{\partial^{2} \rho_{\mathrm{B}}}{\partial y^{2}}+\frac{\partial^{2} \rho_{\mathrm{B}}}{\partial z^{2}}\right) \\
D_{\mathrm{AB}}=\frac{0.0101 T^{1.75} \sqrt{\frac{1}{\mathrm{M}_{\mathrm{A}}}+\frac{1}{\mathrm{M}_{\mathrm{B}}}}}{P\left[\sum V_{A}^{1 / 3}+\sum V_{B}^{1 / 3}\right]^{2}}
\end{gathered}
$$

\subsection{Boundary conditions and solution settings}

The turbulence model is a standard $\mathrm{k}-\varepsilon$ model, the inlet boundary condition is set as the velocity inlet, and the outlet boundary condition is the outflow. The physical parameters of the selected materials for the numerical 
simulation are shown in Table 1, and the boundary conditions are set as shown in Table 2. The Mixture in the Multiphase Model module is selected for calculation, and the Euler phase number is selected as 2 .

Table 1 Source phase parameters

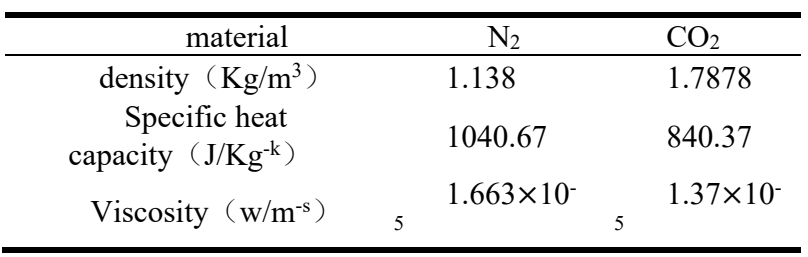

Table 2 Setting of boundary conditions

\begin{tabular}{|c|c|c|}
\hline \multirow{3}{*}{$\mathrm{CO}_{2}$} & speed entry $(\mathrm{m} / \mathrm{s})$ & 50 \\
\hline & Volume fraction & 1 \\
\hline & $\mathrm{T}(\mathrm{K})$ & 240 \\
\hline \multirow{3}{*}{$\mathrm{N}_{2}$} & $\mathrm{~V}(\mathrm{~m} / \mathrm{s})$ & 50 \\
\hline & Volume fraction & 1 \\
\hline & $\mathrm{T}(\mathrm{K})$ & 100 \\
\hline outlet & $\mathrm{P}(\mathrm{Pa})$ & 101000 \\
\hline \multirow{3}{*}{ wall } & Wall motion & Static wall \\
\hline & Shear condition & No slip \\
\hline & Wall roughness & 0 \\
\hline
\end{tabular}

\section{Simulation results and analysis}

Figure 3 is a cross-section of the symmetry plane to observe the temperature change cloud diagram of the two liquids after mixing. It can be seen from Figure 3 that during the mixing process of the two fluids, a temperature transition contact surface is formed at the contact position, and a stable temperature is gradually formed after the heat transfer of the two fluids.

Figure 4 shows the temperature-pressure change curve at the center of the pipeline. It analyzes the temperature and pressure changes at different positions of the main pipe and studies the flow characteristics in the pipe after mixing.

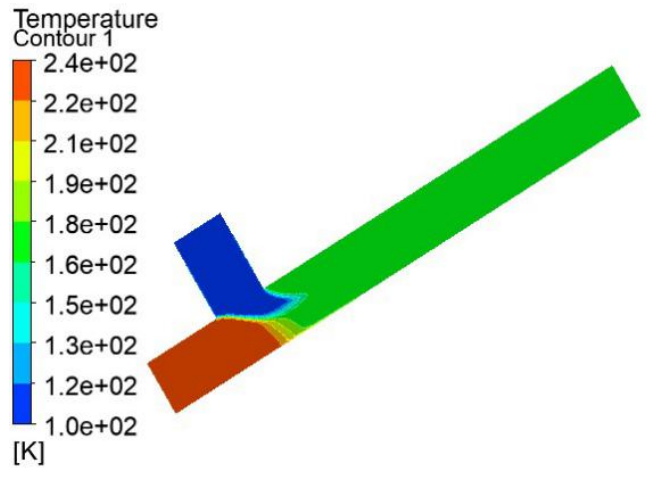

Fig.3 Cloud diagram of temperature distribution in the simulation tube

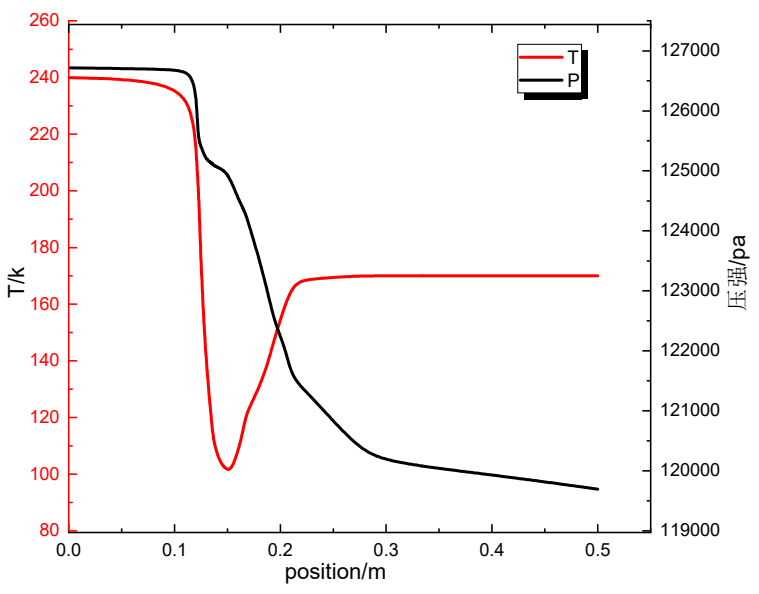

Fig.4 Temperature-pressure curve in simulated tube

It can be seen from Figure 4 that LN2 and CO2 start to mix at 0.1 , and the temperature limit is obvious. Initially, the temperature of LN2 was $100 \mathrm{~K}$, and the temperature of $\mathrm{CO} 2$ was $240 \mathrm{~K}$. After mixing, it quickly dropped to $103 \mathrm{~K}$, and then the temperature rose to $164 \mathrm{~K}$, which was consistent with the equilibrium state in the tube. A gentle and stable phenomenon; as the mixing progresses, the pressure in the pipe shows a downward trend as a whole, and each position along the main pipe produces a positive pressure difference relative to the end of the pipe. The closer to the mixing point, the greater the corresponding pressure difference. With the change of temperature and pressure, $\mathrm{CO} 2$ presents three states: solid, liquid and gas. Under normal pressure, $\mathrm{CO} 2$ has only two phases: gas and solid. At the freezing point, the temperature of atmospheric gas $\mathrm{CO} 2$ can be directly condensed to form dry ice. The freezing point of liquid carbon dioxide is $(196.5 \mathrm{~K}, 0.1 \mathrm{MPa})$. When the pressure is greater than the saturation pressure, gaseous $\mathrm{CO} 2$ condenses into dry ice. In the range of 0.1 to $0.2 \mathrm{~m}$, the phase state of carbon dioxide changes, and solid particles of dry ice appear during the flow.

\section{Experimental verification}

\subsection{Experimental setup}

The experimental device adopts a self-designed and built cryogenic inert gas slurry preparation system, consisting of a low-temperature insulation gas cylinder with a volume of $170 \mathrm{~L}$, a digital display platform scale with a maximum load of $500 \mathrm{~kg}$, a stainless steel pipe with an inner diameter of $20 \mathrm{~mm}$, and a PT100 temperature sensor (temperature range $-197^{\circ} \mathrm{C} 56^{\circ} \mathrm{C}$, current $420 \mathrm{~mA}$ ), $\mathrm{T}=3$ data acquisition instrument, notebook computer, etc. The experimental device is shown in Figure 5: 


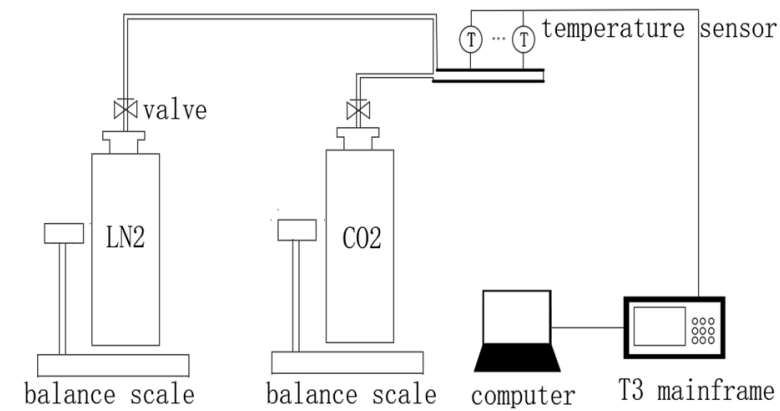

Fig.5 Experimental assembly drawing

\subsection{Experimental procedure}

Check the air-tightness of the device, open the liquid nitrogen valve and let the liquid nitrogen into the pipeline for pre-cooling for 35 minutes. When the temperature drops to $194.5 \mathrm{~K}$, open the $\mathrm{CO} 2$ valve, the design flow rate is $50 \mathrm{~m} / \mathrm{s}$, and the LN21:1 ratio into. The temperature sensors are evenly arranged at a distance of $15 \mathrm{~cm}$ in the cryogenic pipeline, and a total of 9 measuring points are arranged. After the injected fluid is stable, the temperature change in the pipeline is monitored in real time in a period of $10 \mathrm{~s}$.

\subsection{Analysis of experimental results}

By recording the temperature of the measuring point in the pipeline, the temperature change result is shown in Figure 6:

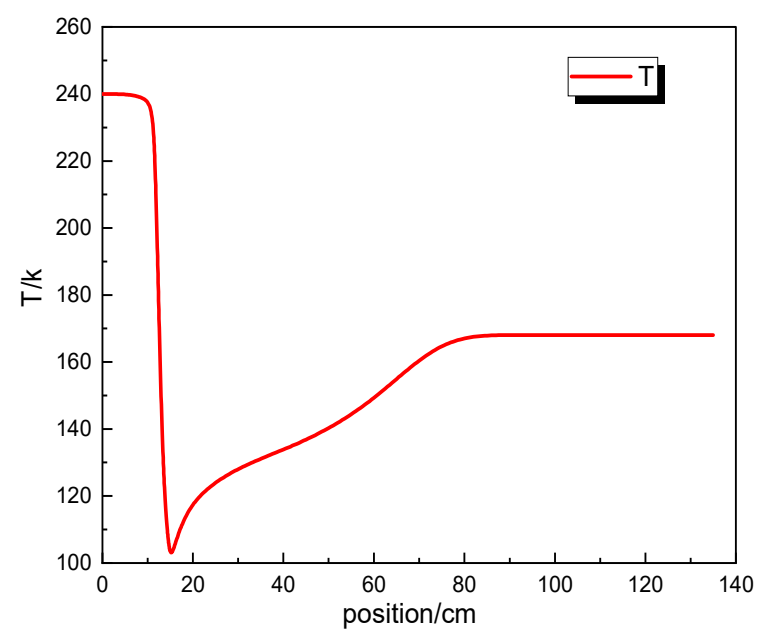

Fig.6 Temperature change curve in test tube

It can be seen from Figure 6 that liquid nitrogen and carbon dioxide mix rapidly in the pipeline, heat exchange occurs at the contact surface, and the temperature changes. Before $0.1 \mathrm{~m}$, it is a rapid cooling stage, and the temperature drops to $103 \mathrm{~K}$. At $0.1 \sim 0.8 \mathrm{~m}$ Within the range, due to the latent heat of carbon dioxide phase change, in the subsequent heat exchange process, the temperature drop rate appears a concave function change trend, the temperature rises to $168 \mathrm{~K}$, and the mixing ends after $0.8 \mathrm{~m}$. The final mixing temperature of the cryogenic inert gas slurry is $168 \mathrm{~K}$. Compared with the results of the numerical simulation, the temperature is higher than that of the numerical simulation. Due to the heat exchange between the cryogenic inert gas slurry and the outside temperature under the action of the pipeline, the temperature of the slurry increases.

\section{Conclusion}

1) Through fluent numerical simulation, the temperature field, pressure field and phase change characteristics in the cryogenic pipe during the mixing process are studied. The results show that the two rapidly mix at $0.1 \mathrm{~m}$ in the cryogenic pipe, and the temperature limit is obvious. After mixing, the temperature is stable at $154 \mathrm{~K}$. The medium pressure decreases continuously as the mixing progresses, and when the sublimation conditions are met, sublimation occurs to produce dry ice particles.

2) According to the experimental visualization results, during the mixing process, due to the role of liquid nitrogen as a low-temperature cold source, heat exchange occurs, and carbon dioxide condenses at low temperature to form granular dry ice particles, which are driven by the jet momentum to form diffuse gas clouds.

3) By comparing with the experimentally measured data, the numerical simulation results are basically consistent with the experimental data, which verifies the reliability of the simulation.

\section{References}

1.XU Tao. Experimental study on the subsection characteristic and mechanism of spontaneous combustion of coal [D]. Xuzhou: China University of Mining and Technology,2012.

2.PAN Shu-ren, PAN Hai-yang, XIE Zhi-qing, et al. Study on coal green exploration technological system under new era background $[\mathrm{J}]$. Coal Geology of China, 2018,30(6):10-13.

3.TAN B, ZHANG F, ZHANG Q, et al. Firefighting of subsurface coal fires with comprehensive techniques for detection and control: a case study of the Fukang coal fire in the Xinjiang region of China [J]. Environmental Science and Pollution Research, 2019, 26(29):1-15.

4.DU Juan. Research on spontaneous under different capacity combustion risk in goaf of high drainage tunnel [J]. Journal of Xi'an University of Science and Technology, 2013, 33(5): 527-531.

5.XIAO Yang, ZHONG Kai-qi, XIE Meng-yue, et al. Experimental research on ionic liquid inhibitors to inhibit coal spontaneous combustion[J].Journal of Xi'an University of Science and Technology, 2017, 37(3): 396-402.

6.LIU Lei, WANG Wei-feng, FENG Yu-long. Numerical simulation of long-distance slurry transport based on FLUENT [J]. Journal of Xi'an University of Science and Technology, 2014,34(2):135-141.

7.MA Li, WANG Wei-feng, DENG Jun, et al. Simulation 
of application technological process of liquid carbon dioxide for goaf fire prevention and control [J]. Journal of Xi'an University of Science and Technology, 2015, 35(2):152-158.

8.YU Zhi-jin, ZHAI Xiao-wei, MA Ling-jun, et al. Evolutional law simulation of high temperature zone of coal spontaneous combustion during retreating period of mining face [J]. Journal of Xi'an University of Science and Technology, 2016, 36(5): 628-632.

9.GAO Yu-kun, LIU Fu-xin, FU Ming-ming, et al. Numerical simulation study on fire preventing and extinguishing technology by dry ice in mined area [J]. Safety in Coal Mines, 2017, 48(1): 32-35.

10.KIM A G. Cryogenic injection to control a coal waste bank fire [J]. International Journal of Coal Geology, 2004, 59(1/2): 63-73.

11.CHAIKEN R F, KIM A G, KOCIBAN A M, et al. Cryogenic slurry for extinguishing underground fires: U.S. Patent 5,368,105[P]. 1994-11-29.

12.ZHANG Xin-hai, ZHENG Zhong-ming, XING Er-jun, et al. A method and device for preventing and extinguishing fire with cryogenic inert gas, CN108005712A [P/OL]. 2017-12-08].

13.ZHANG Xin-hai, ZHENG Zhong-ming, XING Er-jun, et al. A cryogenic inert gas snow and fire prevention device, CN207583424U [P/OL]. 2017-12-08].

14.TAKEUCHI O, HIRONAKA S, SHIMADA Y. Study on Solidification of Carbon Dioxide Using Cold Energy of Liquefied Natural Gas [J]. Heat Transfer Asian Research, 2000, 29(4): 249-268.

15.LI Juan, SHI Yu-mei, WANG Rong-shun. Experimental research on the process of idling $\mathrm{CO}_{2}$ gas into liquid nitrogen with a single pipe $[\mathrm{J}]$. Cryogenics and Superconductivity, 2008,36(1):6-8.

16.Yuan Ling-cheng. Theoretical and experimental investigation of crvogenic $\mathrm{CO}_{2}$ capture by desublimation [D].Hangzhou: Zhejiang University, 2015.

17. Yuan Lingcheng, Jiang Xiaobo, Qiu Limin, et al. Design of observable carbon dioxide desublimation cryogenic experiment device [J]. Cryogenic,2015, (3):30-36.

18.Wang Jianxiong, Jiang Xiaobo, Qiu Limin, et al. Experiment investigation on carbon dioxide capture by cryogenic desublimation [J]. Cryogenic, 2018, (1):47-52.

19.LIU Yao. Research on anti-sublimation characteristics of carbon dioxide in natural gas[D]. Shanghai: Shanghai Jiaotong University, 2013.

20.LIU Yao, LIN Wen-sheng. Analysis of carbondioxide anti -sublimation heat transfer in natural gas flow in a tube heat exchanger under the third class boundary condition[J]. Cryogenics, 2012, (3): 42-46.

21.Fan Ya-fang. Numerical simulation on desublimation and heat transfer of UF6 gas in an 8L cryogenic container[D]. Beijing :Tsinghua University, 2016.

22.WANG Ya-ning. Transient model of $\mathrm{CO}_{2}$ desublimation and experimental investigation of crystal shape [D]. Hangzhou: Zhejiang University, 2019.

23.WANG Jian-guo, ZHOU Tong-zhu, QI Fei-wen, et al. Numerical simulation of dust movement rules at fullymechanized mining faces in Liangshuijing coal mine [J]. Journal of Xi'an University of Science and Technology, 2020, 40(2):195-203. 